\title{
Herpes Simplex Encephalitis
} with Two False-Negative Cerebrospinal Fluid PCR Tests and Review of Negative PCR Results in the Clinical Setting

\author{
Adam C. Adler ${ }^{\mathrm{a}}$ Srinath Kadimi $^{\mathrm{b}}$ Catherine Apaloo ${ }^{\mathrm{a}}$ \\ Corina Marcu ${ }^{\mathrm{a}}$
}

Departments of a Internal Medicine and 'Neurology, St. Vincent's Medical Center, Bridgeport, Conn., USA

\section{Key Words}

Acyclovir - Encephalitis · False negative · Herpes virus · Polymerase chain reaction

\begin{abstract}
Introduction: Herpes simplex virus encephalitis (HSE) is an acute infection accompanied by significant morbidity and mortality with the diagnosis often made by cerebrospinal fluid (CSF) polymerase chain reaction (PCR) testing.

Case Presentation: We report a case of a healthy 35-year-old woman presenting with altered mental status. Due to suspicion of herpes encephalitis, a CSF PCR for herpes virus was sent for examination and acyclovir was started. The patient had an immediate response to acyclovir; however, when the PCR returned negative she was discharged without therapy. The altered mental status returned and she was started on acyclovir therapy and a second CSF PCR sample was sent and was again negative. MRI performed at initial hospitalization was negative, but a repeat MRI demonstrated bilateral temporal lobe involvement suggestive of herpes encephalitis. The patient was successfully treated for 21 days with acyclovir.

Conclusion: CSF PCR for herpes virus is highly sensitive and specific and remains the standard for diagnosing herpes encephalitis. Clinicians should be aware of the pitfalls of CSF PCR testing, specifically false-negative results. Although rare, these false negatives can result in premature termination of treatment.
\end{abstract}




\section{Introduction}

Herpes simplex virus encephalitis (HSE) is an acute infection accompanied by significant morbidity and mortality [1]. Clinically, HSE has a prodrome of fever, headache, seizure, focal neurologic signs, and altered consciousness [2]; however, mild or atypical presentations have been reported [3-9]. The diagnosis of HSE is generally clinical with confirmatory tests including lumbar puncture and cerebrospinal fluid (CSF) polymerase chain reaction (PCR) testing. Auxiliary tests to aid diagnosis include electroencephalogram (EEG), computed tomography (CT), and especially magnetic resonance imaging (MRI). We present a patient initially suspected to have HSE although with a negative MRI and CSF examination including PCR for herpes simplex virus (HSV). The patient was started on acyclovir with an initial response but was discharged after the PCR was negative. The patient returned with worsening symptoms, this time with MRI and EEG both suggestive of HSE; however, repeat CSF PCR for HSV was again negative. The high sensitivity and specificity of PCR for HSV leads physicians to rely on this test for making or excluding the diagnosis of HSE, although false-negative results may occur. Cases with a high pre-test probability for HSE and suggestive MRI and/or EEG examinations, although with two false-negative PCR tests, are seldom encountered or reported in the literature.

\section{Case Report}

A 35-year-old Hispanic female without a significant past medical history arrived at the emergency department complaining of headache, dizziness, nausea, and vomiting for 2 days prior to admission. The dizziness and nausea were connected with food intake. The headache was localized to the frontal region and accompanied by photophobia and phonophobia and six episodes of vomitus. Immediately prior to admission, the patient had had a witnessed generalized seizure of 30-45 s duration without bowel or bladder incontinence and developed postictal confusion without postictal lateralized neurological deficits. At the time of admission, she was disoriented to person, place, and time with a GCS of 9. Initially, she was afebrile and physical examination was without focal findings. Laboratory examination was unremarkable. Lumbar puncture revealed clear fluid with glucose $69 \mathrm{mg} / \mathrm{dl}$, protein 31 $\mathrm{mg} / \mathrm{dl}, 2 \mathrm{WBC}, 3 \mathrm{RBC}$, no monocytes or lymphocytes, and without xanthochromia. CSF bacterial and cryptococcal antigen testing was negative. Urine analysis, toxicology, culture of blood, CSF, and urine were all negative. CSF was sent for HSV-PCR testing. CT scan was without acute pathology. Acyclovir $(10 \mathrm{mg} / \mathrm{kg}$ i.v., 3 times per day) was started as empiric treatment in addition to levetiracetam for seizure prevention. EEG showed generalized slowing suggestive of encephalopathy although it was extremely limited due to patient movement and inability to cooperate. MRI was without acute pathology. Twentyfour hours after initiation of acyclovir the patient was lethargic but not confused. Forty-eight hours following admission, the patient's mental status was reported to be at baseline, GCS 15, and she was eager to return home. Acyclovir was switched to oral preparation and after one dose, the CSF HSV-PCR returned negative, and the patient was discharged without further need to continue antiviral medication. Within $24 \mathrm{~h}$, she returned to the emergency department complaining of severe headaches, vomiting, and an episode of unresponsiveness, slurred speech, and blank starring as reported by family members. At the time of admission, she had intermittent episodes of confusion; however, the remainder of the physical examination was normal. Laboratory examination was again unremarkable. Acyclovir (10 mg/kg i.v., 3 times per day) was restarted. Repeat lumbar puncture was performed with glucose 79 $\mathrm{mg} / \mathrm{dl}$, protein $24 \mathrm{mg} / \mathrm{dl}, 50 \mathrm{WBC}, 17 \mathrm{RBC}$, and negative for xanthochromia, cryptococcal antigen, VDRL, RPR, bacterial antigens, Lyme, West Nile antigen, and CMV antigen. Serum HIV test was nonreactive. CSF HSV-PCR was sent for repeat analysis. After careful consideration of the differential diagnosis of our patient, attempts were made to exclude limbic encephalitis with NMDA receptor antibody test, which was ultimately negative. Overnight, the patient became increasingly confused, delirious, and extremely agitated followed by a witnessed tonic-clonic seizure. Respiratory distress ensued, and due to the inability to protect her airway, intubation and mechanical ventilation was initiated and a loading dose of valproic acid was started for seizure control. She became febrile to a 
maximum of $101.3^{\circ} \mathrm{F}\left(38.5^{\circ} \mathrm{C}\right)$ and developed thick endobronchial secretions identified as Grampositive cocci and Gram-negative rods. She remained febrile with a chest X-ray finding suggestive of developing infiltrate at the right lung base. Repeat EEG demonstrated absence of normal background activity with generalized slowing and presence of periodic lateralized epileptiform discharges. Repeat MRI had increased signal intensity in the medial aspect of the temporal lobes, more marked on the left than on the right, and was felt to be compatible with an acute phase of herpes encephalitis (fig. 1, fig. 2, fig. 3). The second CSF HSV-PCR returned negative. The patient remained encephalopathic for 1 week with minimal improvement during which time her pneumonia resolved. She improved slowly with acyclovir treatment with confusion waning each day. She was transferred to acute rehabilitation where she completed a 21-day course of acyclovir. Three weeks after the second admission, the patient had returned to baseline and was able to leave the medical center.

Written informed consent was obtained from the patient for use of medical information and images for publication of this case report. A copy of the written informed consent is available for review by the Editor-in-Chief of this journal.

\section{Discussion}

With the discovery of PCR, diagnosis of central nervous system infections has become more sensitive and specific, particularly with infections caused by the herpes virus. PCR is considered the standard for the diagnosis of HSE, although specific CSF serologic testing can be employed in cases where suspicion remains high in the setting of a negative PCR test. Retrospective diagnosis can be made with the presence of anti-HSV IgG in the CSF [10]. PCR allows for the detection of minute quantities of viral DNA or RNA present in fluids and tissues by nucleic acid amplification over a short time period [11] and has nearly replaced brain biopsy for diagnosis of HSE in regions where the test can be performed. Negative PCR tests are associated with low CSF protein and leukocyte counts [10], and in such cases, clinical suspicion should dictate the treatment course. The sensitivity and specificity of CSF PCR for HSV exceeds 95\%, allowing exclusion of HSE in patients with high pre-test probability should the result return negative [12]. In the study by Lakeman and Whitley [12], PCR sensitivity and specificity were reported as 98 and $94 \%$, respectively, with positive and negative predictive values of 95 and $98 \%$, respectively, when compared with brain biopsy. However, in patients with high clinical probability of HSE, a negative PCR result, while decreasing the likelihood of HSE, does not entirely exclude the possibility of infection. Negative PCR results generally allow for the discontinuations of acyclovir treatment. Few reports exist identifying HSE in patients with negative PCR [13-15]. Puchhammer-Stockl et al. [14] reported 3 patients with MRI and clinical evidence of HSE with negative PCR tests. Denes et al. [13] reported a series of 3 cases of HSE confirmed by CSF antibody testing in the setting of negative PCR tests. Possible explanations for negative PCR results have been suggested and include: PCR sent very early in the disease development (days 1-4 with neurological symptoms) and viral load too low for detection, although this is unlikely as the PCR technique by virtue of the amplification process allows for the detection of minute amounts of viral copies, as low as 10 copies of viral inhibitors, and a small-volume CSF sample $[11,14,16]$. In addition, low CSF cell counts, variation in primers used during PCR processing, sample dilution, and location of infection in the central nervous system have all been suggested as the cause for false-negatives results $[1,14,17]$. Denes et al. [13] recommend repeating the PCR 4 days after development of symptoms and before deciding the patient does not have HSE and prematurely concluding acyclovir treatment. Patients with normal diagnostic tests and mild clinical symptoms are more likely to have negative PCR tests [18]. In our case, the patient had a repeat PCR sent 6 days after the development of symptoms, and despite 
suggestive MRI and EEG and worsening clinical symptoms, the result was negative. Attempts were made to uncover an alternative diagnosis according to the experiences highlighted by Chataway et al. [19].

Radiographically, the most common areas of involvement are the medial temporal lobes, which are best observed with MRI [20]. Sensitivity of MRI is reported to be best 48 $\mathrm{h}$ after onset of symptoms and approaches $85 \%$ [20], although it can be falsely negative in very early stages on infection. EEG may serve as an occasional adjunct in the diagnosis of HSE, demonstrating periodic lateralized epileptiform discharges as characteristic findings [20]. Specificity of EEG remains low in the diagnosis of HSE when used as a single diagnostic exam but can be helpful when PCR is negative in patients with high clinical probability [20]. In our case, the MRI on initial presentation failed to demonstrate any significant areas of disease, although repeat MRI, 6 days following onset of symptoms, revealed florid changes suggestive of HSV infection.

Acyclovir is the only treatment shown to significantly improve prognosis [21]. The morbidity and mortality increases dramatically as the time to treatment increases [22]. Treatment course is weight based in adults, roughly $10 \mathrm{mg} / \mathrm{kg}$ every $8 \mathrm{~h}$ intravenously for 10-21 days. Repeat MRI after successful treatment with acyclovir is generally unnecessary [23].

\section{Conclusion}

Suspicion of HSE should remain high in all cases of acute encephalitis, especially in the absence of alternative diagnoses, even in cases when PCR examination is negative. In such cases, repeating lumbar puncture should be entertained with repeat HSV-PCR testing and possible serologic testing of the CSF. In our case, the patient had clinical symptoms, MRI and EEG suggestive of HSE, although with two negative PCR tests separated in time. In patients with high clinical suspicion and negative HSV-PCR, repeat lumbar puncture should be considered and empirical acyclovir treatment should be considered. In our case, continuation of acyclovir was warranted and proved efficacious as the patient achieved near-complete resolution. In all such cases, treatment with acyclovir should ensue until the diagnosis of HSE can be confidently excluded.

\section{Disclosure Statement}

The authors report that there are no conflicts of interest. No monetary compensation or grants were received for the preparation of this article. 


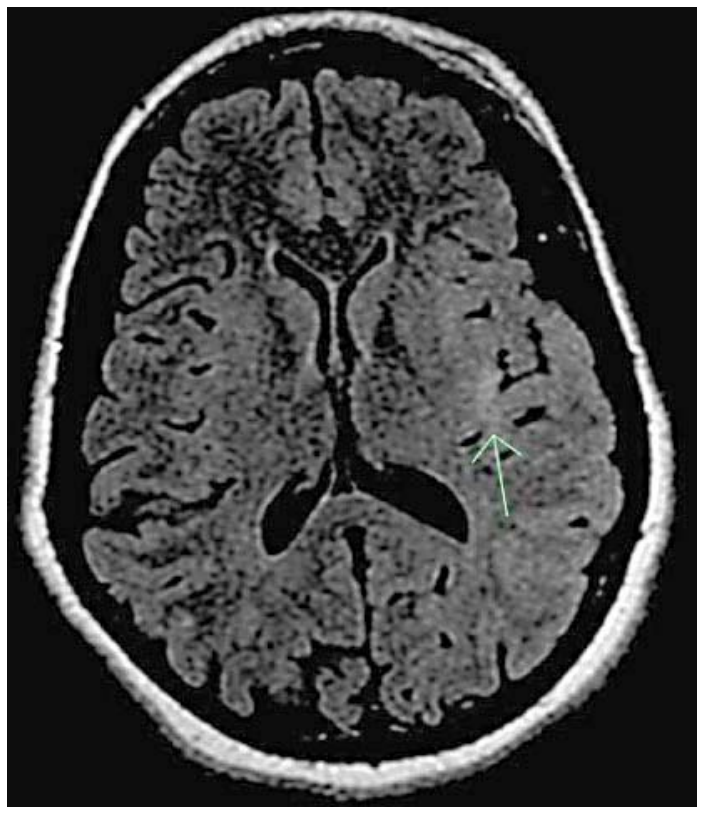

Fig. 1. MRI axial FLAIR with increased signal intensity at the medial temporal lobe (arrow).

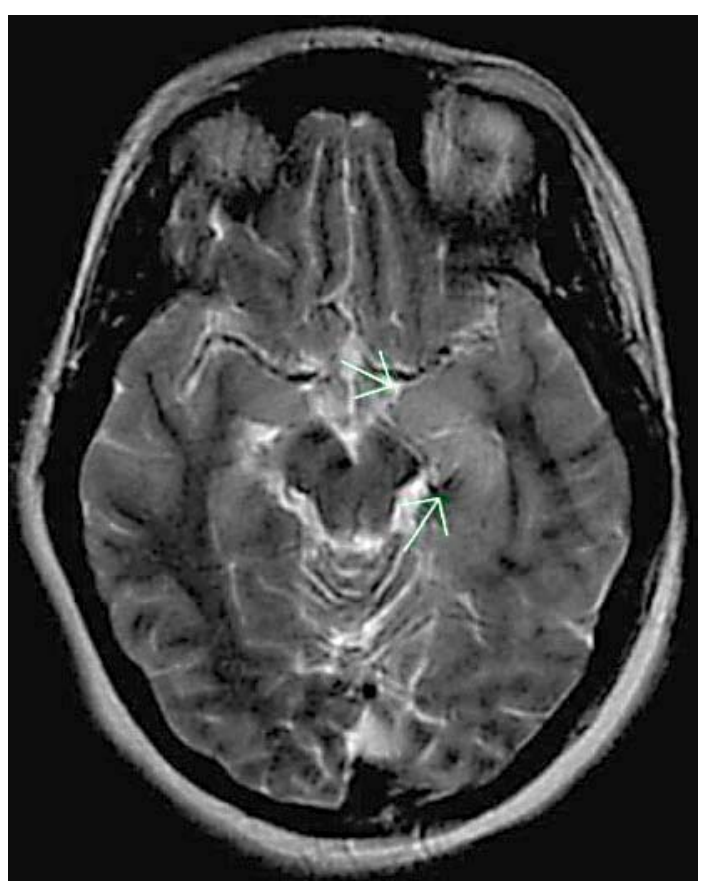

Fig. 2. MRI axial T2-weighted image identifying increased signal intensity at the left temporal lobe (arrows). 


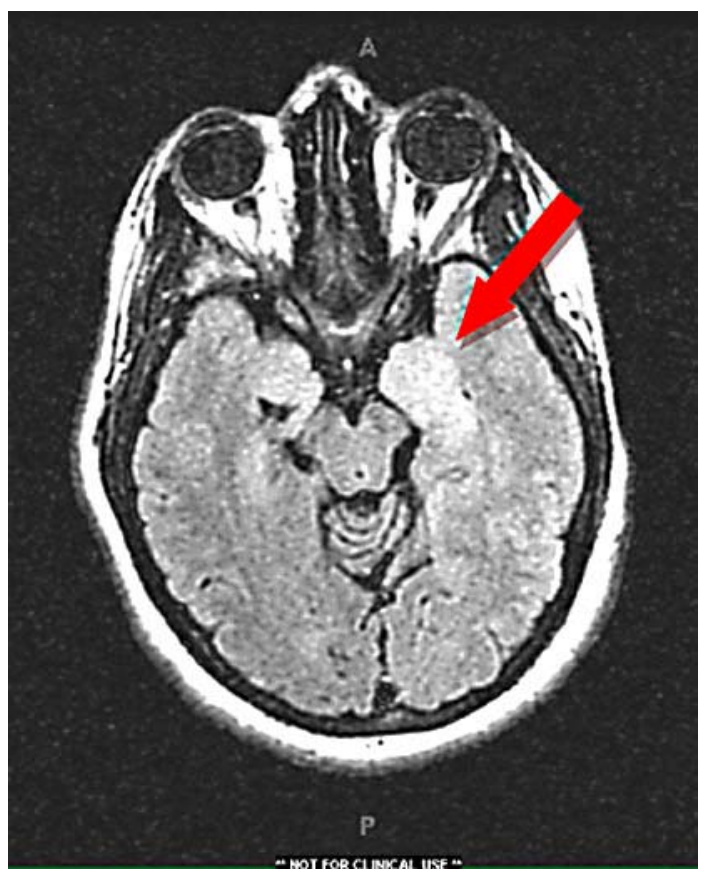

Fig. 3. MRI axial T2-weighted image identifying increased signal intensity at the left temporal lobe (arrow). Image contrast brightened.

\section{References}

1 Domingues RB, Lakeman FD, Mayo MS, Whitley RJ: Application of competitive PCR to cerebrospinal fluid samples from patients with herpes simplex encephalitis. J Clin Microbiol 1998;36:2229-2234.

2 Whitley RJ, Soong SJ, Linneman C Jr, et al: Herpes simplex encephalitis: clinical assessment. JAMA 1982;247:317-320.

-3 Fodor PA, Levin MJ, Weinberg A, Sandberg E, Sylman J, Tyler KL: Atypical herpes simplex virus encephalitis diagnosed by PCR amplification of viral DNA from CSF. Neurology 1998;51:554-559.

4 Klapper PE, Cleator GM, Longson M: Mild forms of herpes encephalitis. J Neurol Neurosurg Psychiatry 1984;47:1247-1250.

5 Shelley BP, Raniga SB, Al-Khabouri J: An unusual late complication of intracerebral haematoma in herpes encephalitis after successful acyclovir treatment. J Neurol Sci 2007;252:177-180.

6 Ohta K, Tabata M, Nakachi I, et al: HSV encephalitis with posterior localization. Neurology 2003;61:862.

7 Ohta K, Funaki M, Tanaka M, Suzuki N: Early cerebellar involvement on diffusion-weighted magnetic resonance images in herpes simplex encephalitis. J Neurol 1999;246:736-738.

8 Gkrania-Klotsas E, Lever AML: Herpes simplex I encephalitis presenting as a brain haemorrhage with normal cerebrospinal fluid analysis: a case report. J Med Case Rep 2008;2:387.

9 Harrison NA, MacDonald BK, Scott G, Kapoor R: Atypical herpes type 2 encephalitis associated with normal MRI imaging. J Neurol Neurosurg Psychiatry 2003;74:974-976.

10 Tiege XD, Rozenberg F, Burlot K, Gaudelus J, Ponsot G, Heron B: Herpes simplex encephalitis: diagnostic problems and late relapse. Dev Med Child Neurol 2006;48:60-63.

11 DeBiasi RL, Kleinschmidt-DeMasters BK, Weinberg A, Tyler KL: Use of PCR for the diagnosis of herpesvirus infections of the central nervous system. J Clin Virol 2002;25:S5-S11.

12 Lakeman FD, Whitley RJ: Diagnosis of herpes simplex encephalitis: application of polymerase chain reaction to cerebrospinal fluid from brain-biopsied patients and correlation with disease. National Institute of Allergy and Infectious Diseases Collaborative Antiviral Study Group. J Infect Dis 1995;171:857-863. 
13 Denes E, Labach C, Durox H, Adoukonou T, Weinbreck P, Magy L, Ranger-Rogez S: Intrathecal synthesis of specific antibodies as a marker of herpes simplex encephalitis in patients with negative PCR. Swiss Med Wkly 2010;140:E1-E4.

-14 Puchhammer-Stockl E, Presterl E, Croy C, Aberle S, Popow-Kraupp T, Kundi M, Hofmann H, Wenninger U, Godl I: Screening for possible failure of herpes simplex virus PCR in cerebrospinal fluid for the diagnosis of herpes simplex encephalitis. J Med Virol 2001;64:531-536.

15 Aurelius E, Johansson B, Skoldenberg B, Forsgren M: Encephalitis in immunocompetent patients due to herpes simplex virus type 1 or 2 as determined by type specific polymerase chain reaction and antibody assays of cerebrospinal fluid. J Med Virol 1993;39:179-186.

16 Selvaraju SB, Wurst M, Horvat RT R.S.: Performance of three different HSV ID/typing assays for detection and typing of herpes simplex virus in cerebrospinal fluid. Diagn Microbiol Infect Dis 2009;63:286-291.

17 Puchhammer-Stockl E, Heinz FX, Kundi M, Popow-Kraupp T, Grimm G, Millner MM, Kunz C: Evaluation of the polymerase chain reaction for diagnosis of herpes simplex virus encephalitis. J Clin Microbiol 1993;31:146148.

18 Domingues RB, Tsanclis AM, Pannuti CS, Mayo MS, Lakeman FD: Evaluation of the range of clinical presentations of herpes simplex encephalitis by using polymerase chain reaction assay of cerebrospinal fluid samples. Clin Infect Dis 1997;25:86-91.

19 Chataway J, Davies NWS, Farmer S, Howard RS, Thompson EJ, Ward KN: Herpes simplex encephalitis: an audit of the use of laboratory diagnostic tests. QJM 2004;97:325-330.

20 Al-Shekhlee A, Kocharian N, Suarez JJ: Re-evaluating the diagnostic methods in herpes simplex encephalitis. Herpes 2006;13:17-19.

-21 Raschilas F, Wolff M, Delatour F, Chaffaut C, De Broucker T, Chevret S, Lebon P, Canton P, Rozenberg F: Outcome of and prognostic factors for herpes simplex encephalitis in adult patients: results of a multicenter study. Clin Infect Dis 2002;35:254-260.

22 Lakeman FD, Whitley RJ: Herpes simplex virus infection of the central nervous system: therapeutic and diagnostic considerations. Clin Infect Dis 1995;20:414-420.

23 Lee JW, Kim I, Kim WS, Yeon KM, Lee H, Hwang YS: Herpes simplex encephalitis: MRI findings in two cases confirmed by polymerase chain reaction assay. Pediatr Radiol 2001;31:619-623. 